\title{
Human lower oesophageal sphincter relaxation is associated with raised cyclic nucleotide content
}

\author{
M S Barnette, F C Barone, P J Fowler, M Grous, W J Price, H S Ormsbee
}

\begin{abstract}
Increases in cyclic adenosine monophosphate and cyclic guanosine monophosphate content accompany relaxation of isolated strips of opossum and canine lower oesophageal sphincter muscle. The aim of this investigation was to characterise these responses in isolated muscle from the human lower oesophageal sphincter. Electrical stimulation of enteric neurons produced a frequency dependent relaxation of the human lower oesophageal sphincter that was sensitive to tetrodotoxin. Furthermore, as previously shown in the opossum and canine lower oesophageal sphincter, cyclic guanosine monophosphate content was significantly raised in muscle strips frozen during maximum electrical field stimulation whereas cyclic adenosine monophosphate content was unchanged. In addition, sodium nitroprusside $\left(\mathrm{EC}_{50}=0 \cdot 1\right.$ $\mu M)$ produced a concentration dependent relaxation of human lower oesophageal sphincter, significantly increased cyclic guanosine monophosphate content, but did not alter cyclic adenosine monophosphate content. Zaprinast (M\&B 22948) and SK\&F 94120 , selective inhibitors of cyclic guanosine monophosphate and cyclic adenosine monophosphate phosphodiesterases, respectively, both relaxed human lower oesophageal sphincter with a potency similar to that seen in the dog or opossum lower oesophageal sphincter. Finally, the 8-bromo analogues of both cyclic adenosine monophosphate $\left(\mathrm{EC}_{50}=420 \mu \mathrm{M}\right)$ and cyclic guanosine monophosphate $\left(E_{50}=100 \mu M\right)$ relaxed the human lower oesophageal sphincter. These studies suggest that in the human, as well as the canine and opossum lower oesophageal sphincter, increases in cyclic nucleotide content are associated with relaxation and increases in cyclic guanosine monophosphate are associated with the relaxation induced by stimulation of enteric neurons.
\end{abstract}

The lower oesophageal sphincter provides a physiological barrier that prevents reflux of gastric contents into the oesophagus.' Indeed, reflux occurs only during transient or prolonged abolition of this high pressure zone. ${ }^{23}$ In man, unlike certain animals, regulation of sphincter tone is, to a large extent, neurogenic, through both excitatory and inhibitory inputs from the vagus nerve. ${ }^{+}$The final common pathway for these inputs is the enteric nervous system. Electrical stimulation of enteric neurons produces a relaxation of the lower oesophageal sphincter in both man and animals. ${ }^{5-7}$ Although the inhibitory neurotransmitters released by this stimulation have not been fully characterised, there is evidence that vasoactive intestinal polypeptide may be one of the substances released by activation of these inhibitory neurons. ${ }^{8}$ More recently, the relaxant response and change in cyclic nucleotides of isolated lower oesophageal sphincter smooth muscle to neuronal stimulation has been characterised. In both the opossum ${ }^{9}$ and canine ${ }^{10}$ lower oesophageal sphincter, activation of the enteric nervous system by electrical stimulation produces a relaxation that is accompanied by a significant increase in cyclic guanosine monophosphate content but not cyclic adenosine monophosphate, whereas, at least in the opossum lower oesophageal sphincter, addition of vasoactive intestinal polypeptide produces a relaxation that is associated with an increase in cyclic adenosine monophosphate. ${ }^{9}$ These findings suggest that in two animal species both cyclic adenosine monophosphate and cyclic guanosine monophosphate may be important intracellular mediators of relaxation in this smooth muscle.

Since most of our current understanding of the biochemistry, physiology, and pharmacology of this smooth muscle comes from animal studies, it must be determined if these animal models mimic the human situation. This is especially important in the development of new treatments for gastrointestinal disease. Therefore, the present study was designed to examine the relaxation response of isolated human lower oesophageal sphincter to electrical field stimulation and to a number of pharmacological agents that change cyclic nucleotide content.

\section{Methods}

\section{TISSUE STUDIES}

Tissue specimens of human gastroesophageal junction were obtained from organ donors through the National Disease Research Interchange (NDRI), Philadelphia, PA. Only samples that arrived less than 14 hours after the aorta had been clamped were used in these experiments as those that took longer to arrive were not viable for study. Upon arrival, these 
iced samples were placed in an oxygenated Krebs bicarbonate buffer $(\mathrm{NaCl}, 117 \cdot 7 \mathrm{mM} ; \mathrm{KCl}, 4 \cdot 7$ $\mathrm{mM} ; \mathrm{CaCl}_{2}, 2 \cdot 5 \mathrm{mM} ; \mathrm{K}_{2} \mathrm{PO}_{4}, 1 \cdot 18 \mathrm{mM} ; \mathrm{MgSO}_{4}$, $1 \cdot 18 \mathrm{mM} ; \mathrm{NaCO}_{3}, 25 \cdot 0 \mathrm{mM}$; glucose, $\left.11 \cdot 1 \mathrm{mM}\right)$. The junction was cut open and the demarcation between gastric and oesophageal mucosa was marked. The mucosa was then removed by sharp dissection and strips of circular smooth muscle $(1.0-1.5 \mathrm{~cm}$ by $0.2 \mathrm{~cm})$ were cut from the gastroesophageal junction.

The tissues were placed in quick release $10 \mathrm{ml}$ organ baths containing oxygenated Krebs buffer at $37^{\circ} \mathrm{C}$. In a preliminary experiment, a tension of $1.5 \mathrm{gm}$ provided the largest tissue response to $10 \mu \mathrm{M}$ acetylcholine - that is, it was the optimum initial tension. Therefore, an initial tension of $1.5 \mathrm{~g}$ was placed on each muscle strip. Tissues were allowed to equilibrate for one hour and were then subjected to an initial maximum electrical field stimulation $(8.0 \mathrm{~Hz}, 1.0 \mathrm{msec}$, $65 \mathrm{v})$. In preliminary experiments, contractile and relaxant responses to electrical field stimulation were determined at various levels of the gastroesophageal junction. In later experiments, only tissues that gained tone and relaxed to electrical field stimulation were considered to be from the lower oesophageal sphincter and were used for further study. Frequency response curves were constructed after obtaining a stable response to the initial maximum test electrical field stimulation. In other tissues, cumulative concentration response curves to zaprinast (M\&B 22948), SK\&F 94120, and sodium nitroprusside were constructed in the presence of atropine $(1 \mu \mathrm{M})$, meclofenamic acid $(1 \mu \mathrm{M})$, phentolamine $(10 \mu \mathrm{M})$, and propranolol (1 $\mu M)$. Relaxation responses were normalised as a percentage of the initial maximum responses to electrical field stimulation response. Usually, the responses of several smooth muscle strips from each specimen were determined under identical conditions. These strips served as replicates and the values obtained were averaged together. For each study, the number of experiments - that is, specimens and replicates - from each specimen are indicated on the Tables and in the Figure legends.

During maximum electrical field stimulation or after the addition of the maximum concentration of test substance, tissues were flash frozen using precooled modified Wollenburger clamps

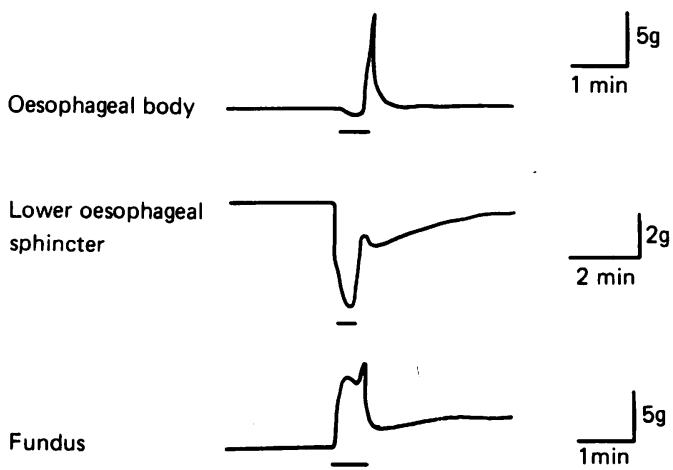

Figure 1: Representative responses of smooth muscle strips from the human lower oesophagus, lower oesophageal

sphincter, and fundus to electrical field stimulation $(8.0 \mathrm{~Hz}$,

$1.0 \mathrm{msec}, 65 \mathrm{v})$. Time and amplitude scales are indicated at the right. and stored at $-70^{\circ} \mathrm{C}$ for subsequent determination of cyclic nucleotide content.

MEASUREMENT OF CYCLIC NUCLEOTIDE CONTENT Cyclic nucleotide content was measured by radioimmunoassay." Individual frozen tissues (10-15 mg) were homogenised in $1.5 \mathrm{ml}$ of ice cold $10 \%$ trichloroacetic acid containing approximately $4000-5000 \mathrm{cpm}$ of ${ }^{3} \mathrm{H}$-cyclic adenosine monophosphate as a marker of recovery for both cyclic adenosine monophosphate and cyclic guanosine monophosphate. Precipitated protein was removed by centrifugation at $3000 \mathrm{~g}$ for $10-15$ minutes. The trichloroacetic acid was removed by four extractions with water saturated ether $(4.5 \mathrm{ml})$. The amount of cyclic adenosine monophosphate or cyclic guanosine monophosphate was determined after acetylation using commercially available kits (New England Nuclear, Boston, MA) and expressed as $\mathrm{pmol} / \mathrm{mg}$ protein (cyclic adenosine monophosphate) or $\mathrm{fmol} / \mathrm{mg}$ protein (cyclic guanosine monophosphate).

Protein concentrations were determined by the method of Lowry, ${ }^{12}$ using bovine serum albumin as a standard.

\section{STATISTICAL ANALYSES}

All data are expressed as mean (SEM). Differences between two means were determined by Student's $t$ tests with $\mathrm{p}<0.05$ considered significant.

\section{MATERIALS}

Cyclic nucleotide radioimmunoassay kits and ${ }^{3} \mathrm{H}$-cyclic adenosine monophosphate were obtained from New England Nuclear. Zaprinast was generously provided by May and Baker Ltd. SK\&F 94120 was provided by Smith Kline and French Laboratories, Welwyn Garden City, UK. Phentolamine was obtained from CibaGeigy and meclofenamic acid from WarnerLambert. All other chemicals were purchased from Sigma Chemical Co.

\section{Results}

Since the lower oesophageal sphincter is not an anatomical sphincter but is defined functionally, the response of human smooth muscle from various levels of the gastroesophageal junction to electrical field stimulation was characterised. Typical responses are shown in Figure 1. Muscle strips obtained from the oesophageal body exhibited a characteristic contraction, produced after the stimulation was terminated, whereas electrical stimulation of the lower oesophageal sphincter region produced a concomitant relaxation. Tissues obtained from the fundic region contracted during maximum electrical field stimulation.

To determine if the relaxation elicited by electrical field stimulation of the human lower oesophageal sphincter was neuronally mediated, the ability of tetrodotoxin to inhibit stimulation induced relaxation was examined. An initial response to a maximal electrical field stimula- 
TABLE I Mean (SEM) cyclic nucleotide content of isolated human lower oesophageal sphincter

\begin{tabular}{|c|c|c|}
\hline Treatment & $\begin{array}{l}\text { Cyclic guanosine } \\
\text { monophosphate } \\
\text { (fmol/mg protein) }\end{array}$ & $\begin{array}{l}\text { Cyclic adenosine } \\
\text { monophosphate } \\
\text { (pmol/mg protein) }\end{array}$ \\
\hline \multirow{2}{*}{$\begin{array}{l}\text { Control } \\
8 \cdot 0 \mathrm{~Hz} \\
\text { Control } \\
\text { Sodium nitroprusside } \\
\quad(300 \mu \mathrm{M})\end{array}$} & $\begin{array}{l}112 \cdot 4(26 \cdot 8)(n=6) \dagger \\
219 \cdot 7(17 \cdot 4)(n=6) \\
198 \cdot 4(93 \cdot 0)(n=3) \ddagger\end{array}$ & $\begin{array}{l}4 \cdot 2(0 \cdot 4)(n=6) \dagger \\
4 \cdot 5(0 \cdot 4)(n=6) \\
3 \cdot 3(0 \cdot 4)(n=3) \ddagger\end{array}$ \\
\hline & $1492 \cdot 8(52 \cdot 0)(n=3)^{\star}$ & $3 \cdot 1(0 \cdot 4)(n=3)$ \\
\hline
\end{tabular}

$\mathrm{n}=$ number of experiments

In this study, $1-6$ strips from each section were frozen and assayed for cyclic nucleotide content.

$\neq$ In this study, 1 strip from each specimen was frozen either in the absence or presence of sodium nitroprusside.

absence or presence of sod.
${ }^{\mathrm{p}} \mathrm{p}<0 \cdot 05$, Student's $t$ test.

tion $(8.0 \mathrm{~Hz})$ was obtained and then tissues were treated with tetrodotoxin $(10 \mu \mathrm{M})$ for 10 minutes and the response to electrical field stimulation was repeated. In these studies tetrodotoxin produced a significant inhibition of the relaxation elicited by electrical stimulation (Fig 2 ). These findings showed that the relaxation produced by electrical stimulation of isolated strips of human lower oesophageal sphincter is neuronally mediated and indicate that the human lower oesophageal sphincter exhibits a tetrodotoxin sensitivity similar to that observed for isolated strips of opossum and canine lower oesophageal sphincter. ${ }^{913}$

In isolated strips of both opossum and canine lower oesophageal sphincter, electrical stimulation produced a frequency dependent relaxation that was accompanied by an increase in cyclic guanosine monophosphate but not cyclic adenosine monophosphate. As shown in Figure 3 , electrical stimulation relaxed isolated human lower oesophageal sphincter in a frequency dependent manner. Furthermore, in tissues frozen during maximum stimulation - that is 8 $\mathrm{Hz}$ - cyclic guanosine monophosphate content was significantly increased whereas cyclic adenosine monophosphate content was unchanged (Table I).

For comparison with our previous studies in other species, the ability of several drugs that have been reported to alter cyclic nucleotide content in other tissues were examined in the isolated human lower oesophageal sphincter. Cumulative addition of sodium nitroprusside, a nitrovasodilator and an activator of the soluble form of guanylate cyclase, ${ }^{14}$ to muscle strips of human lower oesophageal sphincter produced a concentration dependent relaxation of this tissue (Fig 4). Furthermore, in tissues frozen after the addition of $300 \mu \mathrm{M}$ sodium nitroprusside, cyclic guanosine monophosphate content was increased approximately sevenfold without an increase in cyclic adenosine monophosphate values (Table I).

To further characterise the human lower oesophageal sphincter, the ability of two isozyme selective inhibitors of cyclic nucleotide phosphodiesterase to relax the sphincter was examined. Zaprinast, an inhibitor of cyclic guanosine monophosphate selective isozyme produced a concentration dependent relaxation of human tissue (Fig 5). Although cyclic guanosine monophosphate content was increased in all tissues treated with $300 \mu \mathrm{M}$ zaprinast, this increase was not statistically significant, probably because of

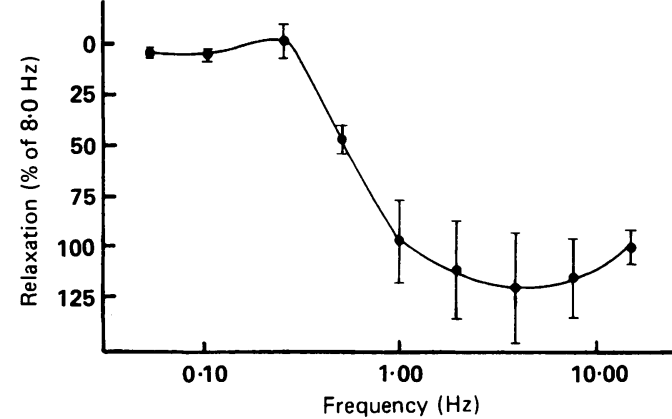

Figure 3: Electrical field stimulation produces a frequency related relaxation of human lower oesophageal sphincter. The data are expressed as percentage of the response to an initial $8.0 \mathrm{~Hz}$ stimulation $(4 \cdot 1(0 \cdot 4) \mathrm{g})$. The values are the mean (SEM) of three experiments. In this study, electrical stimulation induced relaxation was determined in two to four strips of lower oesophageal sphincter from each specimen.

the small sample size and the variation among the samples (Table II). In contrast to zaprinast, SK\&F 94120, an inhibitor of the phosphodiesterase III isozyme that is a cyclic adenosine monophosphate selective phosphodiesterase, ${ }^{15}$ produced a concentration dependent relaxation (Fig 5) that was accompanied by a significant increase in cyclic adenosine monophosphate content without a change in cyclic guanosine monophosphate (Table II).

Finally, the ability of the membrane permeable analogues of cyclic nucleotides to elicit relaxation was determined. As shown previously in the opossum lower oesophageal sphincter, 8-Br-cyclic adenosine monophosphate produced a concentration dependent relaxation of the human sphincter (Fig 6). Furthermore, although less potent than 8 -Br-cyclic guanosine monophosphate, 8-Br-cyclic adenosine monophosphate also produced a concentration dependent relaxation of this tissue (Fig 6).

\section{Discussion}

Before characterising the biochemical changes that occur during relaxation of isolated strips of human lower oesophageal sphincter, it was important to determine if this tissue behaved similarly in the muscle bath as did the isolated opossum or canine sphincter. The initial studies were designed to examine the functional response of isolated strips of smooth muscle from

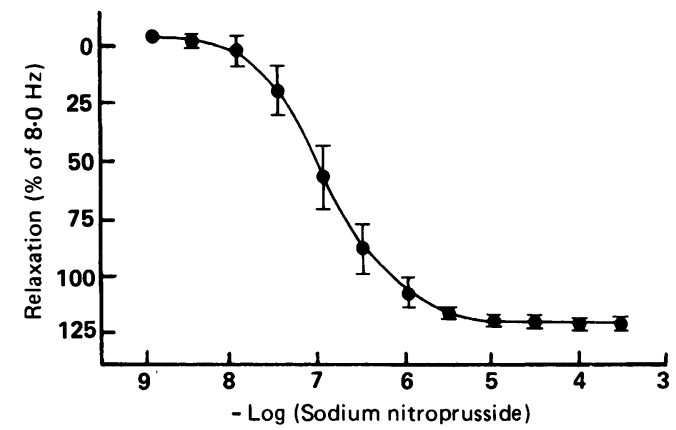

Figure 4: The human lower oesophageal sphincter is relaxed by the cumulative addition of sodium nitroprusside. The data are expressed as percentages of maximal electrical stimulation induced relaxation and are the mean (SEM) of three experiments. Electrical stimulation produced a $4.3(0.9)$ relaxation. In this study, sodium nitroprusside was added to only one strip from each specimen. 


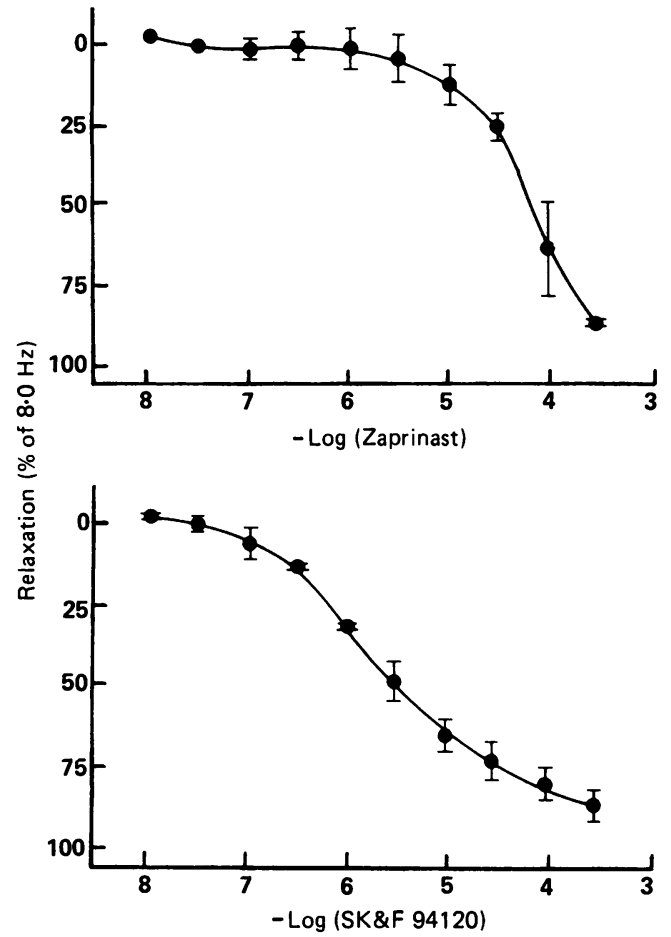

Figure 5: Relaxation of human lower oesophageal sphincter produced by cumulative addition of isozyme selective phosphodiesterase inhibitors, zaprinast and SKE F 94120. The data are expressed as the percentage of maximum electrical field stimulation induced relaxation and are the means (SEM) of three experiments. In these studies, electrical stimulation produced a $4 \cdot 9(1 \cdot 2) \mathrm{g}$ relaxation for zaprinast treated tissues and a 5.2 (1.2) g relaxation for $S K \mathcal{E} F 94120$ treated muscle strips. The effect of cumulative addition of phosphodiesterase inhibitors was determined in one strip from each specimen.

the human gastroesophageal junctional region. In these experiments, electrical field stimulation produced a contraction that occurred at the cessation of the stimulus in muscle strips taken $1-2 \mathrm{~cm}$ above the demarcation of the gastric mucosa. This response is characteristic of muscle from the oesophageal body. ${ }^{16}$ In contrast, electrical stimulation produced a relaxation in muscle strips taken from the oesophageal mucosal junction extending toward the fundic area for about $2 \mathrm{~cm}$. Finally, in muscle strips

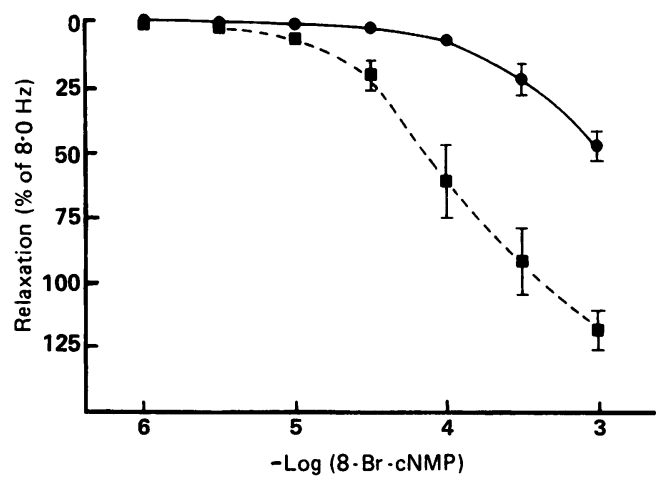

Figure 6: Relaxation of the human lower oesophageal sphincter produced by cumulative addition of 8-Br-cyclic guanidine monophosphate (GMP) (-口-) or 8-Br-cyclic adenosine monophosphate $(A M P)(--)$. The data are expressed as the percentage of maximum electrical field stimulation induced relaxation and are the mean (SEM) of four experiments - that is, specimens. In this study, the cumulative addition of 8-Br-cyclic AMP or 8-Br-cyclic GMP was examined in three to four strips of lower oesophageal sphincter smooth muscle from each specimen. cNMP = cyclic nucleotide monophosphate.
TABLE II Mean (SEM) alterations in cyclic nucleotide content by selective phosphodiesterase inhibitors

\begin{tabular}{lll}
\hline & $\begin{array}{l}\text { Cyclic guanosine } \\
\text { monophosphate } \\
\text { (fmol/mg protein) }\end{array}$ & $\begin{array}{l}\text { Cyclic adenosine } \\
\text { monophosphate } \\
\text { (pmollmg protein) }\end{array}$ \\
\hline Control & $114 \cdot 1(32 \cdot 0)(\mathrm{n}=3) \dagger$ & $2 \cdot 4(0 \cdot 1)(\mathrm{n}=3) \dagger$ \\
Zaprinast $(300 \mu \mathrm{M})$ & $569 \cdot 5(200 \cdot 8)(\mathrm{n}=3)$ & $3 \cdot 7(0 \cdot 5)(\mathrm{n}=3)$ \\
SK\&F 94120 $(300 \mu \mathrm{M})$ & $134 \cdot 5(35 \cdot 4)(\mathrm{n}=3)$ & $4 \cdot 1(0 \cdot 3)(\mathrm{n}=3)^{\star}$ \\
\hline
\end{tabular}

$\mathbf{n}=$ number of experiments.

tIn this study, 1 strip from each specimen was frozen in the absence or presence of the phosphodiesterase inhibitor.

${ }^{\star} \mathrm{p}<0.05$, compared with control, Student's $t$ test.

obtained from 3 to $5 \mathrm{~cm}$ below the demarcation that is, fundic smooth muscle - electrical stimulation produced a contraction during the duration of the stimulation. These findings suggested that muscle strips taken from the human gastroesophageal junction behave in a similar manner to those obtained from animals.

Data obtained from animal studies both in vitro and in vivo have shown that relaxation of the lower oesophageal sphincter is neuronally mediated. ${ }^{7178}$ Although the neurotoxin tetrodotoxin does not always change resting pressure, it blocks the relaxation produced by activation of the enteric nervous system. ${ }^{78}$ In this study and in two earlier reports, tetrodotoxin pretreatment of isolated smooth muscle from the lower oesophageal sphincter inhibited the relaxation produced by electrical stimulation. ${ }^{56}$ These results indicate that the human lower oesophageal sphincter responds in a manner similar to that of the isolated canine and opossum tissue. ${ }^{913}$

In isolated strips of opossum lower oesophageal sphincter, electrical stimulation produces a frequency and time dependent increase in cyclic guanosine monophosphate content that correlates with relaxation. ${ }^{910} 19$ Furthermore, activators of both soluble guanylate cyclase and particulate guanylate cyclase increase cyclic guanosine monophosphate content and relax isolated strips of opossum sphincter, ${ }^{9}$ suggesting that cyclic guanosine monophosphate is an intracellular mediator of relaxation in this tissue. Results obtained in the present study show that cyclic guanosine monophosphate is also raised by electrical field stimulation in muscle strips obtained from the human sphincter. It is important to note that in the present study increases in cyclic guanosine monophosphate occurred during electrical stimulation, either if the data were expressed on an absolute basis (see Table I) or in terms of a percentage change from control values (increased 180 (78)\%). Cyclic adenosine monophosphate, however, did not change during electrical stimulation on an absolute basis (see Table I) or in terms of a percentage change from control values (increased 9 (7)\%). Although both cyclic nucleotides seem to regulate relaxation of the opossum and canine lower oesophageal sphincter, ${ }^{1} 0^{13}$ the present experiments provide the first demonstration of this phenomenon in the human sphincter and suggest that, as in the dog and opossum, cyclic guanosine monophosphate is also an intracellular mediator of neuronally induced relaxation of the human lower oesophageal sphincter. Neuronally mediated relaxation of the bovine 
retractor penis muscle is also associated with an increase in cyclic guanosine monophosphate ${ }^{20}$ also suggesting that the relaxation of some smooth muscles are regulated by this cyclic nucleotide.

Before concluding that cyclic guanosine monophosphate is an intracellular mediator of relaxation in human lower oesophageal sphincter, it should be shown that electrical stimulation produces a frequency and time dependent increase in cyclic guanosine monophosphate content that is consistent with relaxation. In preliminary studies, increasing the frequency of electrical stimulation produced a trend toward increasing cyclic guanosine monophosphate with no change in cyclic adenosine monophosphate. The scarcity of human tissue, however, resulted in a sample size that was small. In addition, tissue scarcity also made it difficult to examine the time dependence of the electrical stimulation induced increase in cyclic guanosine monophosphate content. Although we have been unable to address these questions in detail using human tissues, earlier reports have clearly shown that electrical stimulation produces a frequency dependent increase in cyclic guanosine monophosphate content with no change in cyclic adenosine monophosphate ${ }^{9}$ and that this increase in cyclic guanosine monophosphate content precedes the relaxation. ${ }^{19}$ Also, blocking neuronal activity with tetrodotoxin antagonises the ability of electrical field stimulation to produce relaxation and to increase cyclic guanosine monophosphate in the canine ${ }^{13}$ and opossum ${ }^{9}$ lower oesophageal sphincter. If cyclic guanosine monophosphate is an intracellular mediator of relaxation, then activators of the particulate or soluble forms of guanylate cyclase should produce relaxation and increase cyclic guanosine monophosphate. Cumulative addition of sodium nitroprusside produces a concentration dependent relaxation of the human sphincter. At the maximum concentration tested, sodium nitroprusside increased cyclic guanosine monophosphate content seven fold. Future studies should examine the concentration dependent relation of this response. In the opossum sphincter, cumulative addition of atriopeptin II, a peptide known to activate the particulate form of guanylate cyclase, produces a concentration dependent relaxation and increases cyclic guanosine monophosphate content. ${ }^{910}$ Additionally, it should be shown that inhibitors of cyclic guanosine monophosphate hydrolysis mimic the response to electrical field stimulation. In this study, addition of zaprinast, a selective inhibitor of the type I forms of phosphodiesterase produced a concentration dependent relaxation of the human sphincter. Although in these experiments zaprinast clearly increased cyclic guanosine monophosphate content in all tissues examined, this increase did not reach statistical significance due to the small number of tissues $(n=3)$ that we tested under these conditions. Also, because of the difficulty in obtaining human tissue, it has not been possible to determine if selective phosphodiesterase inhibitors will potentiate the relaxation and increase in cyclic guanosine monophosphate content elicited by electrical stimulation. Further support for the hypothesis that cyclic guanosine monophosphate is an intracellular mediator of relaxation is the finding that a membrane permeable analogue, 8-Br-cyclic guanosine monophosphate, produced a concentration dependent relaxation in the human sphincter. Earlier reports have shown that both cyclic adenosine monophosphate and cyclic guanosine monophosphate dependent protein kinases are present in the human lower oesophageal sphincter. ${ }^{21}$ Future experiments should evaluate the ability of electrical stimulation to alter the activation state of these enzymes. The transmitter released by electrical stimulation that increases cyclic guanosine monophosphate is currently unknown, but it has been shown recently that atrial natriuretic peptide is found in gastrointestinal tissues, ${ }^{22}$ and that atriopeptin II will increase cyclic guanosine monophosphate content of gastrointestinal tissue. ${ }^{93}$ Our results confirm our earlier observations in the lower oesophageal sphincter of the opossum and dog, but, more importantly, show that in human tissue an increase in cyclic guanosine monophosphate content is associated with relaxation and that the electrical stimulation produces an increase in cyclic guanosine monophosphate content.

The results obtained from this study support a role for cyclic guanosine monophosphate in mediating relaxation in the human lower oesophageal sphincter. Also, certain therapeutic approaches for the treatment of hypermotility diseases of the upper gut are suggested. For example, administration of nitrovasodilators might prove beneficial in the treatment of achalasia. Indeed, Wong et al have shown that in people with achalasia, sublingual nitroglycerin produced a significant reduction in sphincter pressure and an improvement in oesophageal emptying. ${ }^{24}$

It has recently become increasingly apparent that there exist several different isozymes of phosphodiesterase within smooth muscle..$^{25} 26$ Each isozyme can be characterised by its distinct kinetic characteristics and substrate specificities, and by its sensitivity to different activators. More importantly, there now exist several selective inhibitors of these different isozymes of phosphodiesterase that can be used as tools to show the functional role of cyclic nucleotide accumulation. Zaprinast is a selective inhibitor of the type I forms of phosphodiesterase. ${ }^{27}$ These isozymes generally display a high affinity for cyclic guanosine monophosphate, although they differ in their affinities for cyclic adenosine monophosphate. ${ }^{28}$ In the present study, the cumulative addition of zaprinast to isolated strips of human lower oesophageal sphincter produced a concentration dependent relaxation. In addition, the present study also showed that cumulative addition of SK\&F 94120, a selective inhibitor of the type III (high affinity for cyclic adenosine monophosphate) phosphodiesterase isozyme, ${ }^{15}$ produced a significant relaxation of the human sphincter and a significant increase in cyclic adenosine monophosphate content. In a similar fashion to the opossum' and canine lower oesophageal sphincter, ${ }^{10}$ addition of a drug that increases cyclic adenosine monophosphate con- 
tent also relaxes isolated strips of the human sphincter. Our findings suggest that compounds that increase cyclic adenosine or guanosine monophosphate content will relax the human lower oesophageal sphincter and may provide therapeutic benefit in the treatment of achalasia.

In conclusion, the present study shows that the isolated human lower oesophageal sphincter responds in a manner similar to that of the opossum and dog. These findings validate the use of these species as models for the human. Of special interest was the finding that electrical field stimulation induced relaxation in human lower oesophageal sphincter smooth muscle strips is also associated with an increase in cyclic guanosine monophosphate, but not cyclic adenosine monophosphate. This result is in agreement with our previous observations in both the opossum and canine lower oesophageal sphincter and supports the hypothesis that cyclic guanosine monophosphate is an intracellular mediator of neuronally induced relaxation.

1 Dodds WJ, Hogan WJ, Helm JF, Dent J. Pathogenesis of reflux esophagitis. Gastroenterology 1981; 81: 376-94.

2 Dent J, Dodds WJ, Friedman RH, et al. Mechanism of gastroesophageal reflux in recumbent asymptomatic human subjects. $\mathcal{F}$ Clin Invest $1980 ; 65 ; 256-67$.

3 Dodds WJ, Dent J, Hogan WJ, et al. Mechanisms of gastroesophageal reflux in patients with reflux esophagitis. NEnglF Med 1982; 307: 1547-52.

4 Dodds WJ, Dent J, Hogan WJ, Arndorfer RC. Effect of atropine on esophageal motor function in humans. $A m \mathcal{F}$ Physiol 1981; 240: 290-6.

5 Burleigh DE. The effects of drugs and electrical field stimulation on the human lower esophageal sphincter. Arch Int Pharmacodyn 1979; 240: 169-76.

6 McKirdy HC, Marshall RW. Effect of drugs and electrical field stimulation on circular muscle strips from human lower field stimulation on circular muscle strips from hum

7 Daniel EE, Crankshaw J, Sarna S. Prostaglandins and tetrodotoxin-insensitive relaxation of opossum lower tetrodotoxin-insensitive relaxation of opossum
esophageal sphincter. Am $\mathcal{F}$ Physiol 1979; 236: 153-72.

8 Biancani P, Walsh JH, Behar J. Vasoactive intestinal polypeptide. A neuropeptide for lower esophageal sphincter relaxation. $f$ Clin Invest 1984; 73: 963-7.

9 Torphy TJ, Fine CJ, Burman M, Barnette MS, Ormsbee HS III. Lower esophageal sphincter relaxation is associated with increased cyclic nucleotide content. Am $\mathcal{F}$ Physiol 1986; 251: 786-93.

10 Barnette MS, Grous M, Torphy TJ, Ormsbee HS III Activation of cyclic AMP dependent protein kinase (cA-PK) is associated with relaxation of canine lower esophageal sphincter by isoproterenol but not by electrical field stimulation (EFS) [Abstract]. Gastroenterology 1986; 91: 1044

11 Brooker G, Harper JF, Terasaki WL, Moylan RD. Radioimmunoassay of cyclic AMP and cyclic GMP. Adv Cyclic Nuc Prot Phosphoryl Res 1979; 10: 1-33.

12 Lowry OH, Rosebrough NJ, Farr AL, Randall RJ. Protein measurement with Folin phenol reagent. $\mathcal{F}$ Biol Chem 1951; 193: $265-75$.

13 Grous M, Ormsbee HS III, Barnette MS. DMPP-induced relaxation of canine lower esophageal sphincter (LES) is associated with an elevation of cyclic GMP content [Abstract]. Gastroenterology 1987; 92: 1417.

14 Ignarro LJ, Kadowitz PJ. The pharmacological and physiological role of cyclic GMP in vascular smooth muscle logical role of cyclic GMP in vascular smooth musc

15 Gristwood RW, Owen DAA, Reeves ML. Phosphodiesterases in guinea pig cardiac ventricle: Specific inhibition of type III activity of SK\&F 94120 [Abstract]. Br F Pharmacol 1985; 85: 224P.

16 Christensen J, Conklin JL, Freeman BW. Physiologic specialization at esophagogastric junction in three species. Am F Physiol 1973; 225: 1265-70.

17 Tuch A, Cohen S. Lower esophageal sphincter relaxation: Studies on the neurogenic inhibitory mechanism. F Clin Invest 1973; 53: 14-20.

18 Goyal RK, Rattan S. Genesis of basal sphincter pressure: Effect of tetrodotoxin on lower esophageal sphincter Effect of tetrodotoxin on lower esophageal sphincter
pressure in opossum in vivo. Gastroenterology 1976; 71: 62-7.

19 Ormsbee HS III, Barnette MS, Grous M, Torphy J. Cyclic GMP (cGMP): a possible second messenger for neurallymediated relaxation of opossum LES [Abstract]. Gastroenterology 1986; 90: 1574 .

20 Bowman A, Drummond AH. Cyclic GMP mediates neurogenic relaxation in the bovine retractor penis muscle. $\mathrm{Br} \mathcal{F}$ Pharmacol 1984; 81: 665-74.

21 Miller CA, Barnette MS, Ormsbee HS III, Torphy TJ. Cyclic nucleotide-dependent protein kinases in the lower esophageal sphincter. Am F Physiol 1986; 251: 794-803.

22 Vuolteenaha $\mathrm{O}$, Arjama O, Vakkuri O, et al. Atrial natriuretic peptide (AMP) in rat gastrointestinal tract. Febs Lett 1988; 233: 79-82.

23 Waldman SA, Rapoport RM, Murad F. Atrial natriuretic factor selectively activates particulate guanylate cyclase and elevates cyclic GMP in rat tissues. F Biol Chem 1984; 259 : $14332-4$

24 Wong RKH, Maydonovitch C, Garcia JE, Johnson LF, Castell DO. The effect of terbutaline sulfate, nitroglycerin, and aminophylline on lower esophageal sphincter pressure and radionucleotide esophageal emptying in patients and achalasia. F Clin Gastroenterol 1987; 9: 386-9.

25 Beavo JA, Hansen RS, Harrison SA, Hurwitz RL, Martin TJ, Mumby MC. Identification and properties of cyclic nucleotide phosphodiesterases. Mol Cell Endocrinol 1982; 28: 387410 .

26 Weishaar RE, Burrows SD, Kobylarz DC, Quade MM, Evan DB. Multiple molecular forms of cyclic nucleotide phosphodiesterase in cardiac and smooth muscle and in platelets. Biochem Pharmacol 1986; 35: 787-800.

27 Bergstrand H, Kristoffersson J, Lundquist B, Schurmann A. Effects of antiallergic agents, compound $48 / 80$ and some reference inhibitors of partially purified human lung tissue adenosine cyclic $3^{\prime}, 5^{\prime}$, monophosphate and guanosine cyclic $3^{\prime}, 5^{\prime}$, monophosphate phosphodiesterase. Mol Pharmacol 1977; 13: 38-43.

28 Hidaka H, Endo T. Selective inhibitors of three forms of cyclic nucleotide phosphodiesterase - basic potential clinical applications. Adv Cyclic Nuc Prot Phosphor Res 1984; 16: 245-59. 